\title{
Performance of mixed ordinary and high strength steel reinforced concrete frames against earthquakes
}

\author{
A. U. Qazi ${ }^{1}$, L. $\mathrm{Ye}^{2} \&$ X. $\mathrm{Lu}^{2}$ \\ ${ }^{1}$ Civil Engineering Department, U.E.T, Lahore, Pakistan \\ ${ }^{2}$ Civil Engineering Department, Tsinghua University, Beijing, China
}

\begin{abstract}
Earthquakes are still claiming lives despite the advancements in earthquake resistance techniques and structural design methodologies. Formations of collapse mechanisms under strong ground motions are not uncommon in RC frames. Failure mechanisms in ordinary RC frames are believed to be prevented by adopting the strong column weak beam philosophy. However, limited flexural strength and lateral deformation capacity of the ordinary steel reinforced columns often results in the incipient of the failure mechanisms. Large inelasticity at the column bases poses serious problems and global stability of the structure is endangered. Furthermore large residual displacements at the end of a dynamic event cannot be ruled out. A numerical study on the performance of frames reinforced with the mixed high strength and ordinary reinforcements in the columns revealed steadier performance as compared to ordinary RC frames. The moderate rise frame, a mixed ordinary and high strength steel reinforced concrete frame (MRC), showed more lateral strength as compared with the ordinary RC frame. Failure mechanisms in the moderate rise MRC frame are almost prevented or delayed as compared with the ordinary RC frame. In the relatively high rise MRC frame, a less obvious increase in lateral strength in comparison with the ordinary RC frame is observed. However, greater deformation capacity and a delay in the formation of the collapse mechanism are observed in the high rise MRC frame. Residual displacements are also minimized in the MRC frame as compared to the ordinary RC frame. It is envisaged that steady performance of the MRC frame can give a more stable response during earthquakes.
\end{abstract}

Keywords: earthquake, failure mechanisms, residual displacements, mixed reinforcements, steady response. 


\section{Introduction}

The failures of modern structures under most recent earthquakes such as Kobe and Northridge have exposed a weakness in the current design techniques and philosophies. In performance based design, although structures are designed for the desired performance target under the probable dynamic event, the formation of failure mechanisms and large residual displacements in structures that have survived strong motions are not uncommon [1]. In frames designed according to the strong column and weak beam concept, plastic hinges are confined to the beam ends and the first story column bases. Plastic hinges at the column bases are necessary to initiate frame sway [2], since ordinary steel reinforcements have limited strength and elastic deformation capacity. Consequently, flexural strength of the RC columns at the base sections is normally approached when the steel yields. Flexural stiffness also deteriorates after excessive steel yielding under cyclic loadings. Resultantly, formations of collapse mechanisms are inevitable under large lateral sways. Large rehabilitation and strengthening demands also emerge with the excessive yielding of the reinforcements in the columns. In order to provide greater lateral strength and deformation capacity in ordinary RC frames, high strength steel as reinforcement in the columns is investigated. Nonlinear static pushover and dynamic analysis are performed in order to study the response benefits.

\section{Numerical analysis and material models}

In this study, a fibre model for RC structures referred to as THUFIBER [3,4], which is based on the general-purpose finite element package of MSC.MARC, is used. In this fibre model, the concrete and steel are modelled with different fibres so that the cyclic behaviour of material can be properly simulated. Users can define the position, area and constitutive model of each fibre. For the nonlinear structural analysis with the fibre model, uni-axial constitutive relations for the concrete and steel are used. For concrete, the compressive stress-strain model proposed by Legeron and Paultre [5] as shown in Fig. 1(a) is used. For monotonic tensile loading a linear stress strain relation also proposed by Legeron and Paultre [6] is used. The stress strain relation for cyclic loading as shown in Fig. 1(b) is used. The unloading curve adopted here is similar to the approach adopted by Mander et al [7]. This model uses the crack closure function [8], which provides a stiffness recovery procedure from tension to compression and models the crack closure mechanism. For steel, a relatively simple relation for monotonic loading proposed by Esmaeily and Xiao [9] shown in Fig. 2(a) and (b) is used. This model with four parameters $K 1, K 2, K 3$ and $K 4$ is versatile and can be tuned to simulate different steel behaviours. For hysteretic behaviour during cyclic loading, a simplified model given by Legeron et al [8] shown in Fig. 3 is used. For mathematical modelling, beam elements are used as finite elements and section behaviour is defined by using THUFIBER. Each cross section is discretized into 30 concrete and four steel fibres. The cover concrete is 
selected with a thickness of $25 \mathrm{~mm}$. The shear strength of the frames is assumed enough and hence only behaviour in flexure is studied. Further, a perfect bond between steel and concrete is assumed.

\section{Frame geometry and material properties}

Two six and ten story bare frames are analyzed. The frames are designed according to ACI 318-02 [10] using ordinary steel as reinforcement in the beams

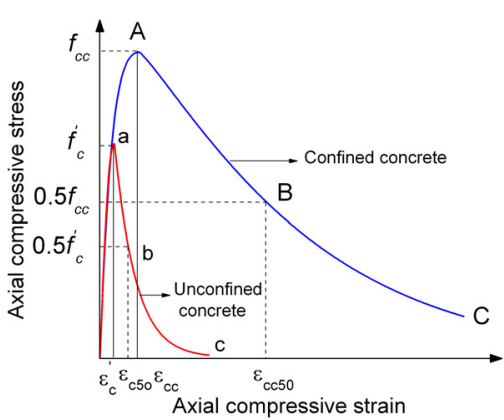

(a)

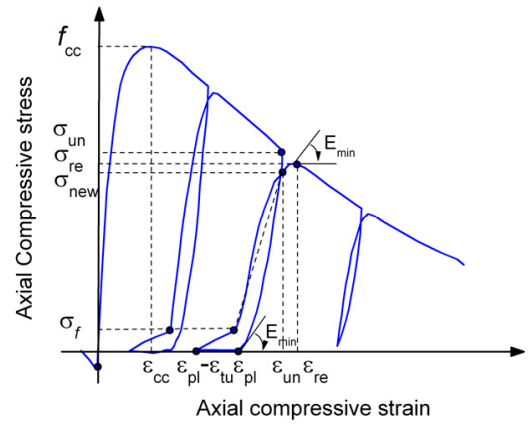

(b)

Figure 1: Stress strain relation for concrete.

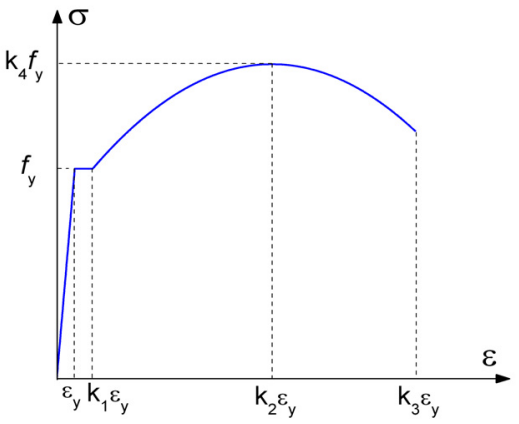

(a)

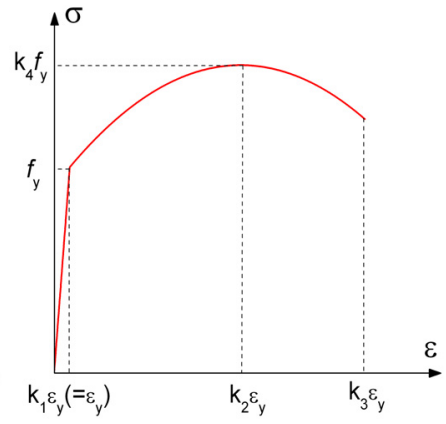

(b)

Figure 2: $\quad$ Steel stress strain relation for steel.

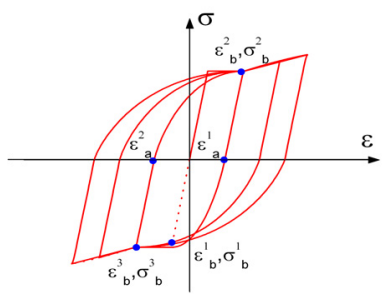

Figure 3: Hysteretic stress strain relation for steel. 
and columns (OFs). Material properties and reinforcement ratios are given in tables 1 and 2 for the six and ten story frames. The response of the OFs is compared with the mixed proportions of ordinary and high strength steel reinforced concrete frames (MRCs). $20 \%$ and $50 \%$ of the ordinary steel in the columns of the OFs was replaced with high strength steel; these columns are named MRC20 and MRC50 respectively. The response of the frames designed with complete replacement of the ordinary reinforcements in the columns of the OFs with high strength reinforcements (abbreviated as PFs) is also investigated. Further, in the lower two stories ordinary steel in the OFs is replaced with high strength steel (referred to as PFS2). The frames are uniformly loaded with 30 $\mathrm{kN} / \mathrm{m}$ gravity loading including the self weight of the beams at all the floor levels. The geometric details of the frames are shown in Fig. 4. $f^{\prime} c$ is the compressive strength of the concrete; $\sigma u$ is the ultimate strength of the concrete. $\varepsilon o$ and $\varepsilon u$ are the strains at compressive and ultimate strength of the concrete. $f y$ and $\varepsilon y$ are the yield strength and yield strain of the longitudinal reinforcement.

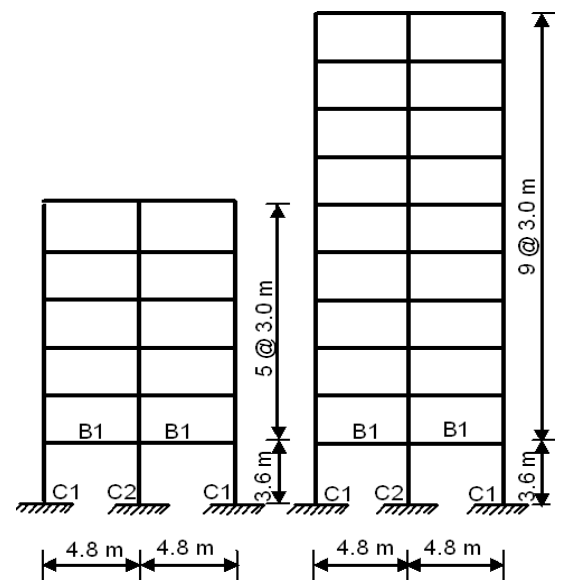

Figure 4: Geometry of the studied frames.

Table 1: $\quad$ Material properties.

\begin{tabular}{|c|c|c|c|c|c|c|c|c|}
\hline \multicolumn{6}{|c|}{ Concrete } & \multicolumn{3}{|c|}{ Steel } \\
\hline$f_{c}($ & $\mathrm{MPa})$ & $\sigma_{u}$ & (MPa) & \multirow{2}{*}{$\varepsilon_{o}$} & \multirow{2}{*}{$\varepsilon_{u}$} & \multicolumn{2}{|c|}{$f_{y}(\mathrm{MPa})$} & \multirow{2}{*}{$\varepsilon_{y}$} \\
\hline Beams & Columns & Beams & $\overline{\text { Columns }}$ & & & Beams & Columns & \\
\hline 25 & 30 & 15 & 20 & 0.002 & 0.004 & 400 & 400 & 0.002 \\
\hline 25 & 30 & 15 & 20 & 0.002 & 0.004 & 400 & 1860 & 0.0093 \\
\hline
\end{tabular}


Table 2: Cross-sectional areas and longitudinal reinforcement ratios of the frames.

\begin{tabular}{|c|c|c|c|c|c|}
\hline \multirow{2}{*}{ Frame } & \multirow{2}{*}{$\begin{array}{l}\text { Story/ } \\
\text { Floor }\end{array}$} & \multicolumn{2}{|l|}{ Column } & \multicolumn{2}{|c|}{ Beam } \\
\hline & & Sections (mm) & $\rho^{a}(\%)$ & Sections $(\mathrm{mm})$ & $\rho^{\mathrm{b}}(\%)$ \\
\hline \multirow{12}{*}{$\begin{array}{l}\text { six } \\
\text { story }\end{array}$} & \multirow{2}{*}{$1^{\text {st }}$} & C1 (400X450) & 1.2 & \multirow{2}{*}{ B1 (250X450) } & \multirow{2}{*}{1.1} \\
\hline & & C2 (400X500) & 1.3 & & \\
\hline & \multirow{2}{*}{$2^{\text {nd }}$} & C1 (400X450) & 1.2 & \multirow{2}{*}{ B1 (250X450) } & \multirow{2}{*}{1.1} \\
\hline & & C2 (400X500) & 1.3 & & \\
\hline & \multirow{2}{*}{$3^{\text {rd }}$} & C1 (400X400) & 1.1 & \multirow{2}{*}{ B1 (250X450) } & \multirow{2}{*}{1.0} \\
\hline & & C2 (400X450) & 1.2 & & \\
\hline & \multirow{2}{*}{$4^{\text {th }}$} & C1 (400X400) & 1.1 & \multirow{2}{*}{ B1 (250X450) } & \multirow{2}{*}{1.0} \\
\hline & & C2 (400X450) & 1.2 & & \\
\hline & \multirow{2}{*}{$5^{\text {th }}$} & C1 (400X400) & 1.1 & \multirow{2}{*}{ B1 (250X450) } & \multirow{2}{*}{1.0} \\
\hline & & C2 (400X450) & 1.2 & & \\
\hline & \multirow[t]{2}{*}{$6^{\text {th }}$} & C1 (400X400) & 1.1 & \multirow{2}{*}{ B1 (250X450) } & \multirow[t]{2}{*}{0.9} \\
\hline & & C2 (400X450) & 1.2 & & \\
\hline \multirow{19}{*}{$\begin{array}{l}\text { Ten } \\
\text { story }\end{array}$} & \multirow{2}{*}{$1^{\text {st }}$} & C1 (400X475) & 1.3 & \multirow{2}{*}{ B1 (300X450) } & \multirow{2}{*}{1.1} \\
\hline & & C2 (400X550) & 1.5 & & \\
\hline & \multirow{2}{*}{$2^{\text {nd }}$} & C1 (400X475) & 1.3 & \multirow{2}{*}{ B1 (300X450) } & \multirow{2}{*}{1.1} \\
\hline & & C2 (400X500) & 1.5 & & \\
\hline & $3^{\text {rd }}$ & C1 (400X450) & 1.2 & B1 (250X450) & 1.0 \\
\hline & 0 & C2 (400X500) & 1.4 & DI & 1.0 \\
\hline & $4^{\text {th }}$ & C1 (400X450) & 1.2 & B1 (250X450) & 1.0 \\
\hline & & C2 (400X500) & 1.4 & (2000400 & 1.0 \\
\hline & $5^{\text {th }}$ & C1 (400X450) & 1.2 & B1 (250X450) & 1.0 \\
\hline & & C2 (400X500) & 1.4 & 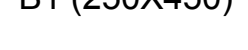 & 1.0 \\
\hline & $6^{\text {th }}$ & C1 (400X450) & 1.2 & B1 (250X450) & 0.9 \\
\hline & & C2 (400X500) & 1.4 & 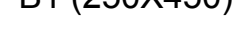 & 0.0 \\
\hline & $7^{\text {th }}$ & C1 (400X400) & 1.0 & B1 (250X450) & 0.9 \\
\hline & & C2 (400X450) & 1.2 & 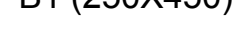 & (0.5 \\
\hline & $8^{\text {th }}$ & C1 (400X400) & 1.0 & B1 (250X450) & 0.9 \\
\hline & & C2 (400X450) & 1.2 & 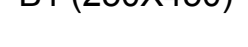 & 0.0 \\
\hline & $9^{\text {th }}$ & C1 (400X400) & 1.0 & B1 (250X450) & 0.9 \\
\hline & & C2 (400X450) & 1.2 & & 0.0 \\
\hline & $10^{\text {th }}$ & $\begin{array}{l}\text { C1 (400X400) } \\
\text { C2 (400X450) }\end{array}$ & $\begin{array}{l}1.0 \\
1.2\end{array}$ & B1 (250X450) & 0.8 \\
\hline
\end{tabular}

${ }^{\mathrm{a}}$ Total area of steel/gross section area; ${ }^{\mathrm{b}}$ Area of tension steel/effective section area. 


\section{Discussion on nonlinear static pushover analysis results}

Inverted triangular monotonic lateral loads are applied and the pushover curves are shown in Fig. 5.

The first occurrences of performance limits as proposed by FEMA-356 [11], namely immediate occupancy (IO), life safety (LS), and collapse prevention (CP), are marked on the curves. Greater strength and deformation capacity is evident for the six stories using MRC50, PFS2 and PF as compared to those using OF. Moreover, performance limits were approached at the beam ends $\left(\mathrm{IO}_{\mathrm{b}}\right.$, $\mathrm{LS}_{\mathrm{b}}$ and $\mathrm{CP}_{\mathrm{b}}$ ) in MRC50, PFS2 and PF. MRC20, however, showed lower strength and deformation capacity than MRC50, PFS2 and PF. Further, life safety $\left(\mathrm{LS}_{\mathrm{c}}\right)$ and collapse prevention $\left(\mathrm{CP}_{\mathrm{c}}\right)$ performance limits first occurred at the column ends. The MRC20 response showed more similarity with the OF, while MRC50 and PFS2 closely matched in lateral strength and deformation capacity with PF. The close similarity in response between ten story MRC50, PFS2 and PF is evident from Fig. (5b). After the occurrence of collapse prevention $\left(\mathrm{CP}_{\mathrm{b}}\right)$, the MRC20 performance limit at one of the beam end sections showed a strength capacity lower than that of MRC50, PFS2 and PF. Performance limits were approached at the beam ends for MRCs, PFS2 and PF. While in contrast, OF showed excessive yielding both at the beam and column end sections and little increase in lateral load resistance was observed after the collapse prevention $\left(\mathrm{CP}_{\mathfrak{c}}\right)$ performance limit in OF. The less lateral deformation capacity of ten story OF is obvious as compared with MRCs, PFS2 and PF.

It is mentionable here that in six and ten story MRCs when ordinary steel in the columns approached its yield strength, the high strength steel was in the elastic range. Hence, in the absence of yielding of high strength reinforcements, the flexural strength of the columns did not approach maximum and the columns' critical sections are saved from complete failure.

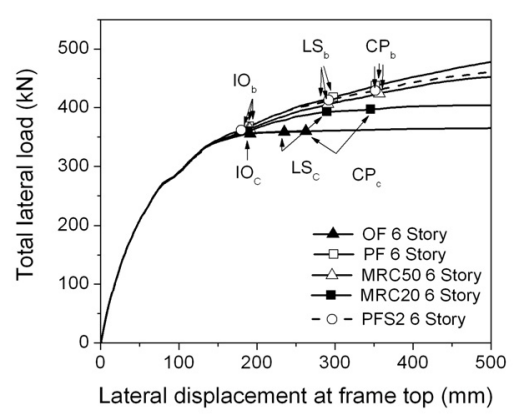

(a)

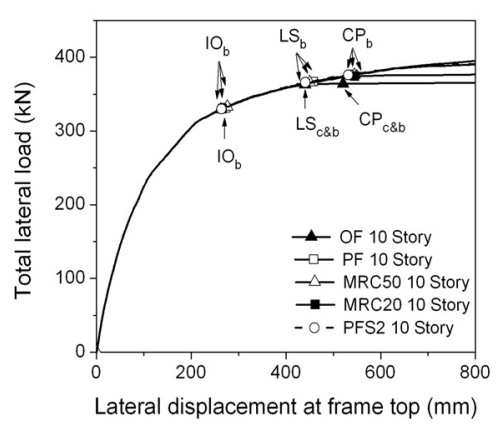

(b)

Figure 5: $\quad$ Pushover curves of six and ten story frames. 


\section{Discussion on nonlinear time history analysis results}

In this study various earthquake records available on the website of the Pacific Earthquake Engineering Research Centre (PEER) (http://peer.berkeley.edu) are studied. However, for the brevity of discussion only the response from the Superstition Hills earthquake is presented in detail. To study the response under extreme shaking, Superstition Hills is scaled from 0.5 to $0.6 \mathrm{~g}$ with $0.1 \mathrm{~g}$ increments. A five percent damping ratio is considered.

\subsection{Top displacement history}

Collapse occurred in the six story $\mathrm{OF}$ and results did not converge after $21.8 \mathrm{secs}$ and $16.4 \mathrm{secs}$ at PGA $0.5 \mathrm{~g}$ and $0.6 \mathrm{~g}$ respectively (Fig. 6(a) and (b)). At PGA $0.6 \mathrm{~g}$, PFS2 also showed failure and non-convergence occurred at $24.5 \mathrm{secs}$. MRC50 showed good similarity in response with PF. The ten story top displacement history of MRCs showed a similarity in response with PF (Fig. 6(c) and (d)). The PFS2 response revealed a more residual lateral shift from the equilibrium position. In the ten story OF, dynamic instability was approached and solutions did not converge after $19.5 \mathrm{secs}$ and $16.2 \mathrm{secs}$ at PGA $0.5 \mathrm{~g}$ and $0.6 \mathrm{~g}$ respectively. In maximum lateral displacements, the MRCs showed close similarity in response with the PF.

\subsection{Maximum interstory drift response}

In the six story frame, the PFS2 maximum story drift revealed more magnitude at the third story than MRCs and PF (Fig. 7). With the increase in the proportion

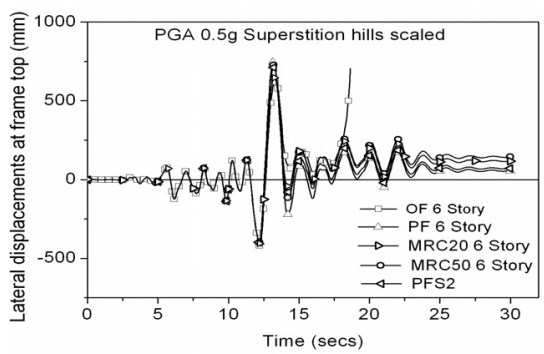

(a)

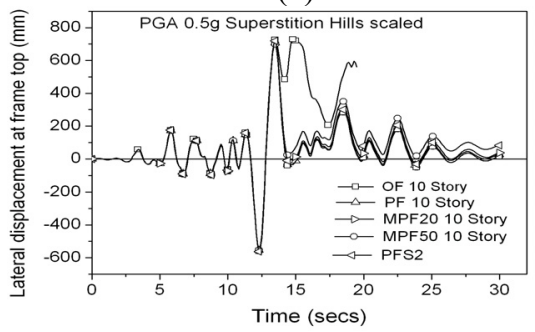

(c)

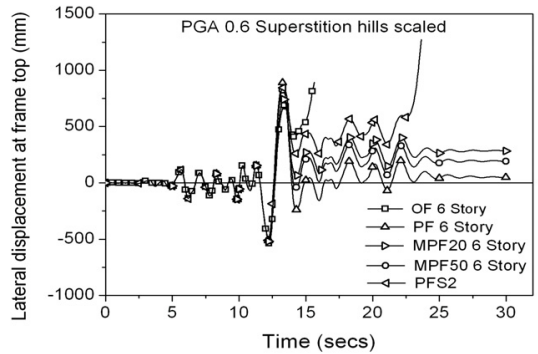

(b)

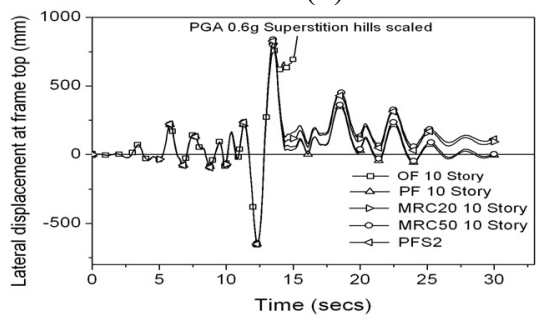

(d)

Figure 6: Top displacement history. 
of high strength reinforcements (MRC20 to MRC50), a gradual decrease in the ground story columns drift accompanied by an increase in the top story drift is observed. OF in the first story showed excessive drift which resulted in failure mechanism. MRC20 in the first story showed comparatively greater drift than MRC50 and PF. Hence it can be stated with the increased proportion of high strength reinforcements, a response comparable to PF can be achieved. In the ten story MRC50, the response almost matched that of all stories with PF. An increase in drift concentration with a sudden drop in story strength is again obvious in PFS2 in the third story. From the observed response it can be concluded that a performance comparable to PF can be realized with MPF50.

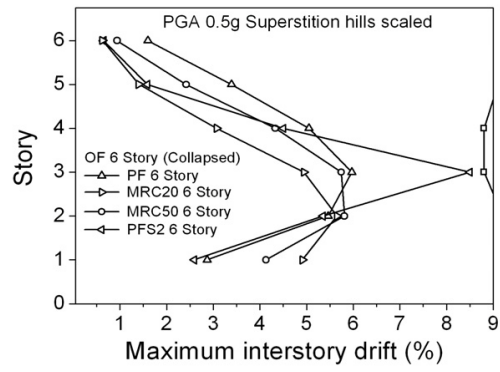

(a)

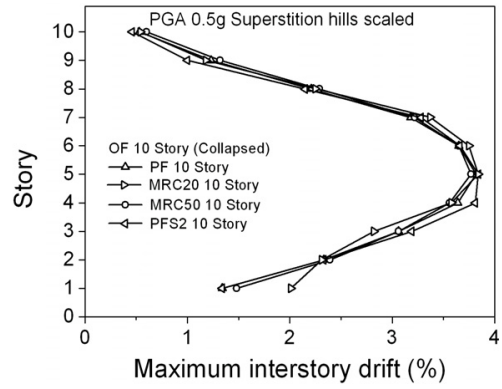

(c)

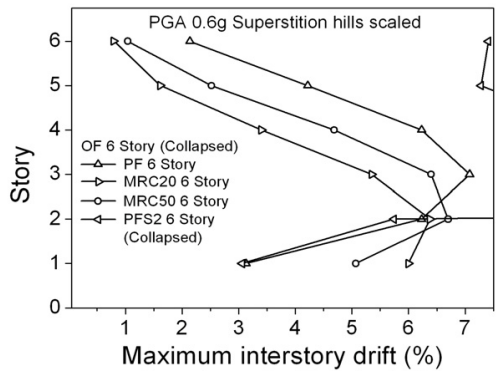

(b)

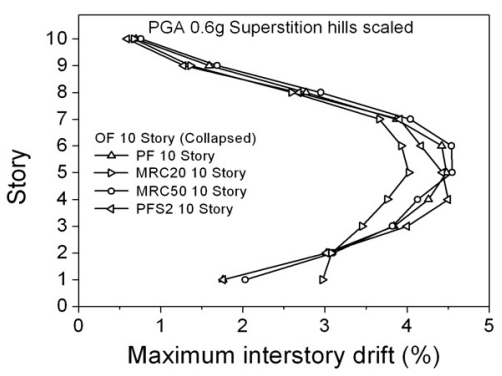

(d)

Figure 7: Maximum interstory drift response

\subsection{Maximum floor acceleration response}

The six story MRC50 and PFS2 responses revealed a close similarity with PF (Fig. 8). However, OF collapsed and the results did not converge after excessive yielding at the ground story columns. At PGA $0.5 \mathrm{~g}$, the ten story MRC50, PFS2 and $\mathrm{PF}$ maximum floor acceleration response nearly matched (Fig. 8(c)). However, OF at the first and second floor showed a large acceleration response when non-convergence occurred. However, MRC50 at $0.6 \mathrm{~g}$ PGA showed a greater response at the intermediate floors as compared with PF (Fig. 8(d)). 
High Performance Structures and Materials IV 355

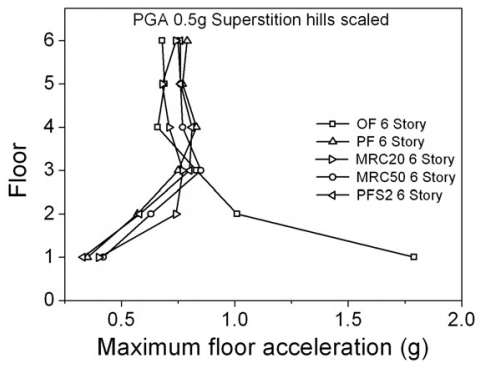

(a)

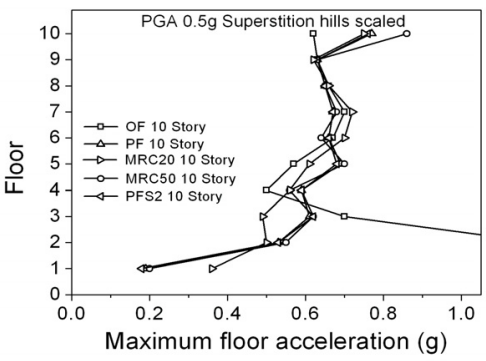

(c)

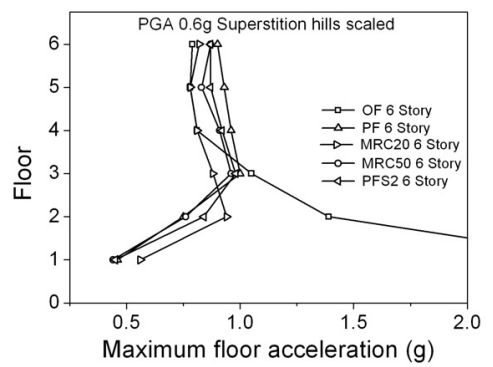

(b)

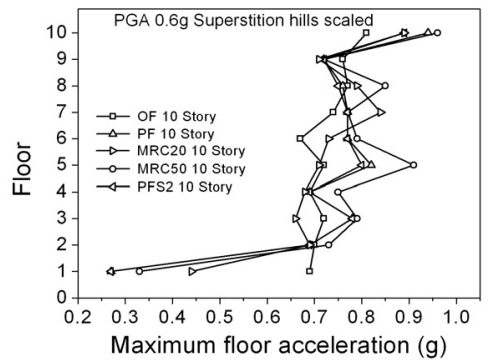

(d)

Figure 8: $\quad$ Maximum floor acceleration response.

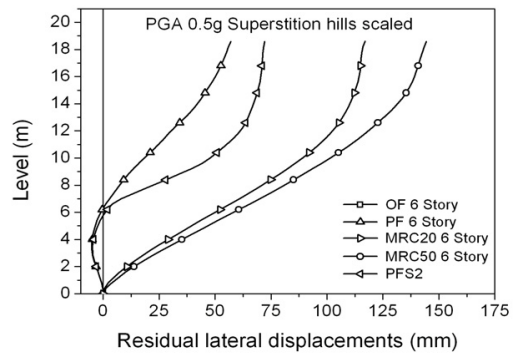

(a)

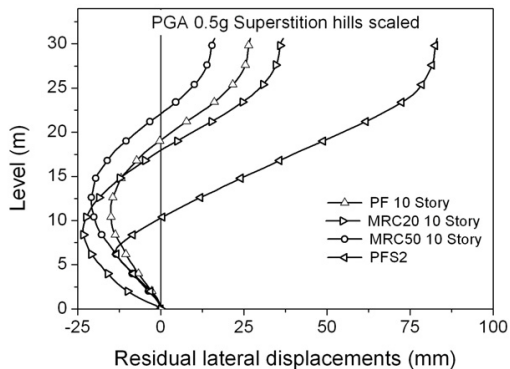

(c)

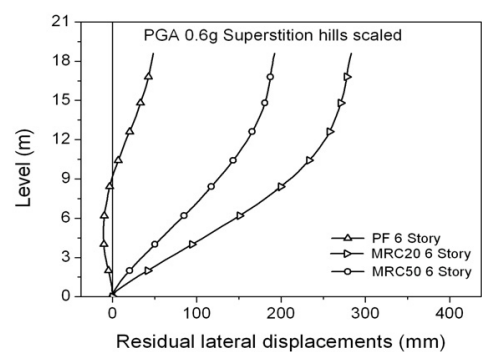

(b)

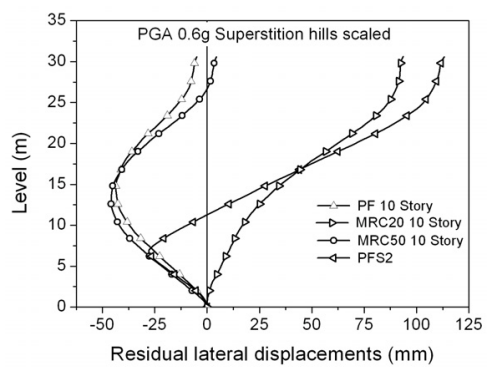

(d)

Figure 9: Residual lateral displacement response. 


\subsection{Residual lateral displacement response}

Residual lateral displacements for six and ten story frames are shown in Fig. 9. In six story frames, MRC20 and MRC50 showed good similarity in response and fewer residual displacements than OF. However, fewer residual displacements are observed in the six story PF. In the ten story frames, the MRC50 response nearly matched that of PF.

\section{Conclusions}

From nonlinear static pushover and time history analysis of six and ten story frames, the following conclusions can be attained.

1. For medium to high rise frames, high strength reinforcements in columns can provide sufficient lateral strength and deformation capacity under strong shaking.

2. For medium to high rise frames, high strength reinforcement in columns can reduce residual lateral displacements.

3. For medium to high rise frames, high strength reinforcements in columns can successfully delay formation of failure mechanisms as are observed in OFs.

4. A mixed proportion of the high strength and ordinary reinforcements in columns can give a response comparable to PF.

5. For medium to high rise frames that are subjected to large earthquakes with columns in the lower stories reinforced with high strength reinforcements, (PFS2) partial mechanism can occur in the above stories. Hence, a sudden decrease in story strengths should be carefully controlled.

6. The maximum floor acceleration response does not show any clear relation with the proportion of ordinary and high strength reinforcements in the frame columns. Hence, the maximum floor accelerations are little effected by ordinary reinforcement yielding in the columns of medium to high rise frames.

\section{References}

[1] Fischer, G. and Li, V. C., "Intrinsic response control of moment resisting frames utilizing advanced composite materials and structural elements." ACI Struct. J., 2003, 100(2), 166-176.

[2] Paulay, T., and Priestley, M. J. N., "Seismic design of reinforced concrete and masonry buildings", Wiley, New York, 1992.

[3] Lu X. Z., Miao Z.W., Huang Y. L., et al. "Simulation for the Collapse of Concrete Tall Building under Static and Dynamic Load." Chengdu, China, 2005. 1-10.

[4] Wang X. L., Lu X. Z., Ye L. P., "Numerical Simulation for the Hysteresis Behavior of Prestressed Concrete Structures under Cyclic Loads." Earthquake Resistant Engineering and Retrofitting, 2006, 28(6):25-29. 
[5] Legeron F., Paultre P., "Uniaxial Confinement Model for Normal- and High-Strength Concrete Columns.” J. Struct. Eng., 2003, 129(2):241-252.

[6] Legeron F., Paultre P., "Damage Mechanics Modeling of Nonlinear Seismic Behavior of Concrete Structures." J. Struct. Eng., 2005, 136(6):946-954.

[7] Mander J. B., Priestley M. J. N., Park R., "Theoretical Stress-Strain Model for Confined Concrete.” J. Struct. Eng., 1988, 114(8):1804-1825.

[8] Legeron F., Paultre P., "Damage Mechanics Modeling of Nonlinear Seismic Behaviour of Concrete Structures". J. Struct. Eng., 2005, 136(6):946-954.

[9] Esmaeily A., Xiao Y., "Behaviour of Reinforced Concrete Columns under Variable Axial Loads: Analysis.” ACI Struct. J., 2005, 102(5):736-744.

[10] American concrete institute (ACI), "Building code requirements for structural concrete and commentary." Detroit, 318-02 edition, 2002.

[11] Federal Emergency Management Agency. "Prestandard and commentary for the seismic rehabilitation of buildings." FEMA-356, Washington, D. C., 2000 . 